\title{
Congruence Lattices of a Finite Isoform Lattices
}

\author{
${ }^{1} \mathrm{~K}$. Thirugnanasambandam, ${ }^{2} \mathrm{~S}$. Mahendrakumar \\ ${ }^{1}$ Department of Mathematics, Govt. Thirumagal Mills College, Gudiyattam-632602, TamiInadu, India. \\ ${ }^{2}$ Research Scholar in Mathematics, Manonmanium Sundaranar University, Tirunelveli,Tamilnadu, India.
}

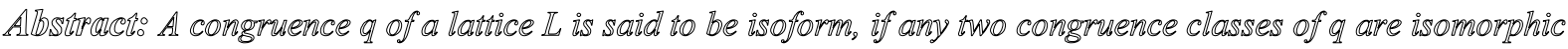
as lautices. The lautice $\mathbb{L}$ is saidd to be is oform, if all congmuence's of $L$ are is foform. We prove that every finnite distributive laticice D can be represented as the congrasence latice of a finite isoform lautice.

\section{Introduction}

In this chapter we study about finite lattices with isoform congruences. We prove that every finite distributive lattice $\mathrm{D}$ can be represented as the congruence lattice of a finite isoform lattice. Infact, we prove that every finite distributive lattice D can be represented as the congruence lattice of a finite lattice $\mathrm{L}$ with the following properties:

(i) $\mathrm{L}$ is isoform

(ii) For every congruence $\theta$ of $\mathrm{L}$, the congruence classes of $\theta$ are projective intervals.

(iii) $\mathrm{L}$ is a finite pruned Boolean lattice.

(iv) $\mathrm{L}$ is discrete -transitive.

This result is a stronger version of the result obtained in the previous chapter. To prove this result, we introduce a new lattice construction which is described in section 1.2. The congruence structure of this new construct is described section 1.3. In section 1.4, we present the proof of the main theorem. We start with the definition of isoform lattices.

\section{DEFINITION: 1.1.1}

Let $\mathrm{L}$ be a lattice. Let $\theta$ be a congruence of $\mathrm{L}$. Then $\theta$ is said to be isoform, if any two congruence classes of $\theta$ are isomorphic as lattices.

\section{DEFINITION: 1.1.2}

A lattice $\mathrm{L}$ is said to be isoform if all congruences of $\mathrm{L}$ are isoform.

\section{DEFINITION: 1.1.3}

A lattice $\mathrm{L}$ is said to be regular, if whenever two congruences share a congruence class, then the congruences are the same.

NOTE: 1.1.4

An isoform lattice is always regular.

\section{NOTATION: 1.1.5}

For a lattice $\mathrm{L}$, we denote by $\omega_{\mathrm{L}}$ and $\mathrm{i}_{\mathrm{L}}$ the smallest and the largest congruence on $\mathrm{L}$, respectively.

$\mathrm{C}_{\mathrm{n}}$ will denote the $\mathrm{n}$ element chain.

$\mathrm{B}_{\mathrm{n}}$ will denote the Boolean algebra with $2^{\mathrm{n}}$ elements. For a bounded lattice $\mathrm{A}$ with bounds 0 and $1, \mathrm{~A}^{-}$will denote the lattice A- $\{0,1\}$

\section{EXAMPLE: 1.1.6}

Consider the Boolean algebra $\mathrm{B}_{2}$, with 4 elements.

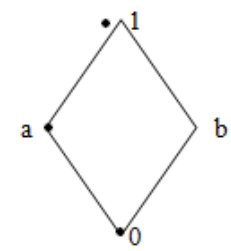

Its congruence lattice is also $\mathrm{B}_{2}$.

It has four congruences, namely, the null congruence $\omega$, the all congruence $i$ and two non-trivial congruences $\theta_{1}$ and $\theta_{2} . \theta_{1}$ has two congruence classes $\{\{0, \mathrm{a}\},\{1, \mathrm{~b}\}\}$ and $\theta_{2}$ has two congruence

classes $\{\{0, \mathrm{~b}\}\},\{\mathrm{a}, 1\}\}$. 
$[0, a]$ and $[b, 1]$ are isomorphic and $[0, b]$ and $[a, 1]$ are isomorphic. So, $\theta_{1}$ and $\theta_{2}$ are isoform congruences. Trivially $\omega$ and $i$ are isoform congruences. Hence $\mathrm{B}_{2}$ is a isoform lattice.

\section{NOTE: 1.1.7}

Every lattice need not be an isoform lattice. For example, the lattice $\mathrm{N}_{6}$, given below is not isoform.

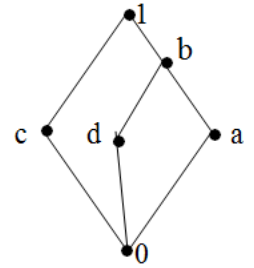

This lattice has exactly one non-trivial congruence $\theta$ and $\theta$ has exactly two congruence classes $\{0, a, b, d\}$ and $\{c, 1\}$. These two congruence classes are not isomorphic.

Hence $\theta$ is not an isoform congruence.

$\therefore \mathrm{L}$ is not an isoform lattice.

\section{DEFINITION: 1.1 .8}

Let $\mathrm{L}$ be a lattice and [a,b] an interval of $\mathrm{L}$. If $\theta$ is a congruence on $\mathrm{L}$, we call $\theta$ discrete on [a,b] or $[a, b]$ is $\theta$-discrete, if $\theta$ and $\omega$ agree on [a,b].

That is $\left.\theta\right|_{[\mathrm{a}, \mathrm{b}]}=\omega_{[\mathrm{a}, \mathrm{b}]}$.

That is $\left.\theta\right|_{[a, b]}=\{(a, a),(b, b)\}$.

\section{DEFINITIO: 1.1.9}

Let $\mathrm{L}$ be a finite lattice. We call $\mathrm{L}$ discrete-transitive, if for any congruence $\Phi$ of $\mathrm{L}$ and for $\mathrm{a}<\mathrm{b}<\mathrm{c}$ in $\mathrm{L}$, whenever $\Phi$ is discrete on $[\mathrm{a}, \mathrm{b}]$ and on $[\mathrm{b}, \mathrm{c}]$ then $\Phi$ is discrete on $[\mathrm{a}, \mathrm{c}]$.

\section{DEFINITION: 1.1.10}

Let $\mathrm{P}=\left(\mathrm{P}, \leq_{\mathrm{P}}\right)$ be a finite poset. Then the partial ordering $\leq_{\mathrm{P}}$ on $\mathrm{P}$ is the reflexive - transitive extension of $\square_{\mathrm{P}}$, the covering relation on $\left(\mathrm{P}, \leq_{\mathrm{P}}\right)$. That is $\operatorname{ReflTr}\left(\square_{\mathrm{P}}\right)=\leq_{\mathrm{P}}$.

Let $H$ be a subset of $\square_{p}$. Take the reflexive-transitive extension $\operatorname{Refl} \operatorname{Tr}(H)$ of $H$. Then $(P, \operatorname{ReflTr}(H))$ is also a poset. This is called as a pruning of $\mathrm{P}$. The diagram of $(\mathrm{P}, \operatorname{Refl} \operatorname{Tr}(\mathrm{H}))$ can be obtained from the diagram of $(\mathrm{P}, \leq)$ by cutting out some edges but not deleting any elements.

\section{DEFINITION: 2.2.1}

\section{A Lattice Construction}

Let $\mathrm{A}$ be a nontrivial finite bounded lattice with bounds 0 and 1 and $|\mathrm{A}|>2$.

Let $\mathrm{B}$ be a nontrivial finite lattice with a discrete transitive

congruence $\theta$.

For $\mathrm{u} \in \mathrm{AxB}$, we use the notation $\mathrm{u}=\left(\mathrm{u}_{\mathrm{A}}, \mathrm{u}_{\mathrm{B}}\right)$ where $\mathrm{u}_{\mathrm{A}} \in \mathrm{A}$ and $\mathrm{u}_{\mathrm{B}} \in \mathrm{B}$. We shall denote by $\leq_{\mathrm{X}}, \square_{\mathrm{X}}, \mathrm{V}_{\mathrm{X}}$ and $\Lambda_{\mathrm{X}}$, the partial ordering, the covering relation, the join and the meet on $\mathrm{AxB}$ respectively.

Let $B_{*}=\{0\} \times B, B^{*}=\{1\} \times B$, and for $b \in B$, let $A_{b}=A x\{b\}$.

We define the set Prune $(A, B, \theta)$ by

Prune $(A, B, \theta)=\left\{\left(\left(a, b_{1}\right),\left(a, b_{2}\right)\right) / a \in A^{-}, b_{1} \square b_{2}\right.$ in $B$ and $\left.b_{1} \equiv b_{2}(\theta)\right\}$.

Then Prune $(A, B, \theta)$ is a subset of $\square_{X}$.

Define $\mathrm{H}=\square_{\mathrm{X}}$ - Prune $(\mathrm{A}, \mathrm{B}, \theta)$.

Consider the reflexive, transitive closure of $\mathrm{H}$.

Then $\operatorname{Refl} \operatorname{Tr}(\mathrm{H})$ is a partial order on $\mathrm{AxB}$.

Define $\mathrm{N}(\mathrm{A}, \mathrm{B}, \theta)=(\mathrm{AxB}, \operatorname{ReflTr}(\mathrm{H}))$

We shall denote the partial ordering $\operatorname{ReflTr}(\mathrm{H})$ on $\mathrm{AxB}$ by $\leq_{\mathrm{N}(\mathrm{A}, \mathrm{B}, \theta)}$ or simply by $\leq_{\mathrm{N}}$.

NOTE: 2.2.2

If $\theta=\omega$, then $\mathrm{N}(\mathrm{A}, \mathrm{B}, \theta)$ is the direct product $\mathrm{AxB}$.

\section{PROPOSITION: 2.2.3}

Let $\mathrm{u}, \mathrm{v} \in \mathrm{AxB}$ and $\mathrm{u} \leq_{\mathrm{X}} \mathrm{v}$. Then $\mathrm{u} \leq_{\mathrm{N}} \mathrm{v}$ if, and only if,

(i) $\mathrm{u}_{\mathrm{A}}, \mathrm{v}_{\mathrm{A}} \in \mathrm{A}^{-}$and $\left[\mathrm{u}_{\mathrm{B}}, \mathrm{v}_{\mathrm{B}}\right]$ is $\theta$ - discrete (or)

(ii) $\mathrm{u}_{\mathrm{A}}$ or $\mathrm{v}_{\mathrm{A}} \notin \mathrm{A}^{-}$ 
Proof :-

Let $\leq_{\mathrm{F}}$ denote the binary relation on $\mathrm{N}(\mathrm{A}, \mathrm{B}, \theta)$ defined by $\mathrm{u} \leq_{\mathrm{F}} \mathrm{V}$ if, and only if, (i) or (ii) holds. We claim that $\leq_{\mathrm{F}}$ is a partial order.

Trivially $\leq_{\mathrm{F}}$ is reflexive and anti-symmetric.

To prove $\leq_{\mathrm{F}}$ is transitive.

Let $\mathrm{u} \leq_{\mathrm{F}} \mathrm{v}$ and $\mathrm{v} \leq_{\mathrm{F}} \mathrm{W}$

Case : 1

Then $\mathrm{u} \leq_{\mathrm{X}} \mathrm{w}$. We have to distinguish some cases.

Both $\mathrm{u} \leq_{\mathrm{F}} \mathrm{v}$ and $\mathrm{v} \leq_{\mathrm{F}} \mathrm{w}$ hold by (i)

Then $\mathrm{u}_{\mathrm{A}}, \mathrm{v}_{\mathrm{A}} \in \mathrm{A}^{-}$and $\mathrm{v}_{\mathrm{A}}, \mathrm{w}_{\mathrm{A}} \in \mathrm{A}^{-}$imply $\mathrm{u}_{\mathrm{A}}, \mathrm{w}_{\mathrm{A}} \in \mathrm{A}^{-}$.

$\left[\mathrm{u}_{\mathrm{B}}, \mathrm{v}_{\mathrm{B}}\right]$ is $\theta$-discrete, $\left[\mathrm{v}_{\mathrm{B}}, \mathrm{w}_{\mathrm{B}}\right]$ is $\theta$-discrete and $\theta$ is discrete transitive imply $\left[\mathrm{u}_{\mathrm{B}}, \mathrm{w}_{\mathrm{B}}\right]$ is $\theta$-discrete.

Hence by (i), $\mathrm{u} \leq_{\mathrm{F}} \mathrm{W}$.

Case : 2

$\mathrm{u} \leq_{\mathrm{F}} \mathrm{v}$ holds by (i) and $\mathrm{v} \leq_{\mathrm{F}} \mathrm{W}$ holds by (ii)

$\therefore \mathrm{u}_{\mathrm{A}}, \mathrm{v}_{\mathrm{A}} \in \mathrm{A}^{-}$and $\left[\mathrm{u}_{\mathrm{B}}, \mathrm{v}_{\mathrm{B}}\right]$ is $\theta$-discrete and $\mathrm{v}_{\mathrm{A}}$ or $\mathrm{w}_{\mathrm{A}} \notin \mathrm{A}^{-}$.

$\mathrm{u}_{\mathrm{A}}, \mathrm{v}_{\mathrm{A}} \in \mathrm{A}^{-}$forces $\mathrm{w}_{\mathrm{A}} \notin \mathrm{A}^{-}$.

Hence by (ii) $\mathrm{u} \leq_{\mathrm{F}} \mathrm{w}$.

Case : 3

$\mathrm{u} \leq_{\mathrm{F}} \mathrm{v}$ holds by (ii) and $\mathrm{v} \leq_{\mathrm{F}} \mathrm{w}$ holds by (i)

$\mathrm{u} \leq_{\mathrm{F}} \mathrm{v}$ holds by (ii) implies either $\mathrm{u}_{\mathrm{A}}$ or $\mathrm{v}_{\mathrm{A}} \notin \mathrm{A}$

$\mathrm{v} \leq_{\mathrm{F}} \mathrm{W}$ holds by (i) implies $\mathrm{v}_{\mathrm{A}}, \mathrm{w}_{\mathrm{A}}, \in \mathrm{A}^{-}$and $\left[\mathrm{v}_{\mathrm{B}}, \mathrm{w}_{\mathrm{B}}\right]$ is $\theta$-discrete.

$\mathrm{v}_{\mathrm{A}}, \mathrm{w}_{\mathrm{A}}, \in \mathrm{A}^{-}$and $\mathrm{u}_{\mathrm{A}}$ or $\mathrm{v}_{\mathrm{A}} \notin \mathrm{A}^{-}$forces $\mathrm{u}_{\mathrm{A}} \notin \mathrm{A}^{-}$.

Case 4:

$\mathrm{u}_{\mathrm{A}} \notin \mathrm{A}^{-}$implies $\mathrm{u} \leq_{\mathrm{F}} \mathrm{W}$ by (ii).

Both $\mathrm{u} \leq_{\mathrm{F}} \mathrm{V}$ and $\mathrm{v} \leq_{\mathrm{F}}$ w holds by (ii).

That is, $\mathrm{u}_{\mathrm{A}}$ or $\mathrm{v}_{\mathrm{A}} \notin \mathrm{A}^{-}$and $\mathrm{v}_{\mathrm{A}}$ or $\mathrm{w}_{\mathrm{A}} \notin \mathrm{A}^{-}$

If $\mathrm{u}_{\mathrm{A}}$ or $\mathrm{w}_{\mathrm{A}} \notin \mathrm{A}^{-}$, then by (ii) $\mathrm{u} \leq_{\mathrm{F}} \mathrm{w}$ holds.

Suppose that $\mathrm{u}_{\mathrm{A}}, \mathrm{w}_{\mathrm{A}} \in \mathrm{A}^{-}$. Then $\mathrm{v}_{\mathrm{A}} \notin \mathrm{A}^{-}$.

$\therefore \mathrm{v}_{\mathrm{A}}=0$ or 1 and $\mathrm{u}_{\mathrm{A}} \leq_{\mathrm{X}} \mathrm{v}_{\mathrm{A}} \leq_{\mathrm{X}} \mathrm{w}_{\mathrm{A}}$

If $\mathrm{v}_{\mathrm{A}}=0$, then $\mathrm{u}_{\mathrm{A}}=0$, contradicting that $\mathrm{u}_{\mathrm{A}} \in \mathrm{A}^{-}$.

If $\mathrm{v}_{\mathrm{A}}=1$, the $\mathrm{w}_{\mathrm{A}}=1$, contradicting that $\mathrm{w}_{\mathrm{A}} \in \mathrm{A}^{-}$.

These two contradictions prove that $\mathrm{v}_{\mathrm{A}} \notin \mathrm{A}^{-}$is impossible.

$\therefore$ Either $\mathrm{u}_{\mathrm{A}}$ or $\mathrm{w}_{\mathrm{A}} \notin \mathrm{A}$

Hence $\mathrm{u} \leq_{\mathrm{F}} \mathrm{W}$ holds.

$\therefore \leq_{\mathrm{F}}$ is a partial order.

If $\mathrm{u} \square \mathrm{v}$, then $\mathrm{u} \leq_{\mathrm{F}} \mathrm{v}$ if, and only if, $\mathrm{u} \leq_{\mathrm{N}} \mathrm{v}$

Hence $\leq_{\mathrm{F}}=\leq_{\mathrm{N}}$

Hence the proposition.

NOTE :2.2.4

$\mathrm{u} \leq_{\mathrm{X}} \mathrm{v}$ and $\mathrm{u} \Leftarrow_{\mathrm{N}} \mathrm{v}$ if, and only if,

$\mathrm{u}_{\mathrm{A}}, \mathrm{v}_{\mathrm{A}} \in \mathrm{A}^{-}$and $\left[\mathrm{u}_{\mathrm{B}}, \mathrm{v}_{\mathrm{B}}\right]$ is not $\theta$ - discrete.

EXAMPLE: 2.2.5

Let $\mathrm{A}=\mathrm{B}_{2}$ and $\mathrm{B}=\mathrm{C}_{4}$ and $\left.\theta=\theta_{(\mathrm{b}, \mathrm{b}}\right)$
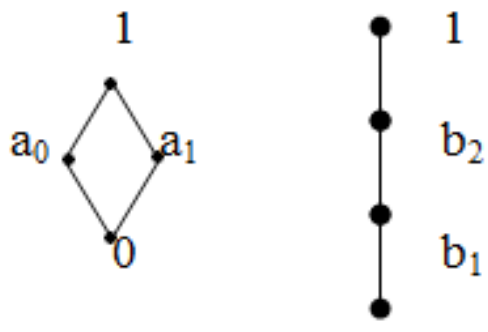

0 
Then $\theta$ is discrete transitive. The lattice $\mathrm{N}(\mathrm{A}, \mathrm{B}, \theta)$ is given below.

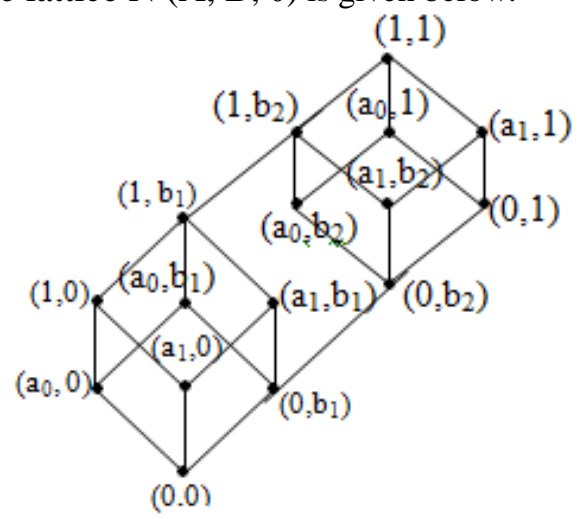

LEMMA: 2.2.6

$\mathrm{N}(\mathrm{A}, \mathrm{B}, \theta)$ is a lattice under the partial ordering $\leq_{\mathrm{N}}$. The meet and join in $\mathrm{N}(\mathrm{A}, \mathrm{B}, \theta)$ can be computed using the formulae.

(*) $\mathrm{u} \Lambda_{\mathrm{N}} \mathrm{V}= \begin{cases}\mathrm{u} \Lambda_{\mathrm{X}} \mathrm{v} & \text { if } \mathrm{u} \Lambda_{\mathrm{X}} \mathrm{v} \leq{ }_{\mathrm{N}} \mathrm{u} \text { and } \mathrm{u} \Lambda_{\mathrm{X}} \mathrm{v} \leq_{\mathrm{N}} \mathrm{v} \\ \left(0, \mathrm{u}_{\mathrm{B}} \Lambda \mathrm{v}_{\mathrm{B}}\right), & \text { otherwise }\end{cases}$

and

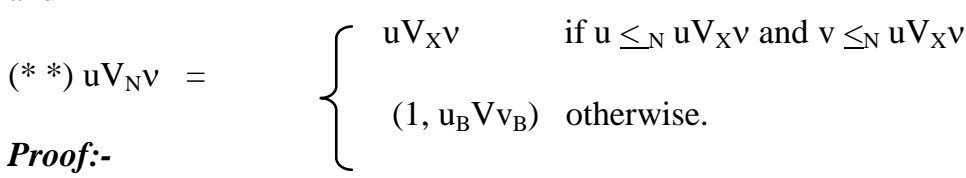

Case 1:

Let $\mathrm{u}, \mathrm{v} \in \mathrm{A} \times \mathrm{B}$ and let $\mathrm{t}$ be a lower bound of $\mathrm{u}$ and $v$ in $\mathrm{N}(\mathrm{A}, \mathrm{B}, \theta)$.

$\mathrm{u} \Lambda_{\mathrm{X}} v$ is not a lower bound of both $\mathrm{u}$ and $v$ in $\mathrm{N}(\mathrm{A}, \mathrm{B}, \theta)$.

Suppose $\mathrm{u} \Lambda_{\mathrm{X}} v \Leftarrow \mathrm{u}$.

Then by (1.2.4), $\mathrm{u}_{\mathrm{A}} \Lambda \mathrm{v}_{\mathrm{A}}, \mathrm{u}_{\mathrm{A}} \in \mathrm{A}^{-}$and $\left[\mathrm{u}_{\mathrm{B}} \Lambda \mathrm{v}_{\mathrm{B}}, \mathrm{u}_{\mathrm{B}}\right]$ is not $\theta$-discrete.

It follows that $\left[\mathrm{t}, \mathrm{u}_{\mathrm{B}}\right]$ is not $\theta$-discrete.

So, $\mathrm{t} \leq_{\mathrm{N}} \mathrm{u}$ implies by (ii) of proposition (1.2.3), $\mathrm{t}_{\mathrm{A}} \notin \mathrm{A}$.

We cannot have $t_{A}=1$, for it will imply $u_{A}=1$, contradicting $u_{A} \in A^{\text {. }}$.

Therefore $\mathrm{t}_{\mathrm{A}}=0$.

Therefore $\mathrm{t} \leq\left(0, \mathrm{u}_{\mathrm{B}} \Lambda \mathrm{v}_{\mathrm{B}}\right)$.

Hence $\mathrm{u} \Lambda_{\mathrm{N}} \mathrm{v}=\left(0, \mathrm{u}_{\mathrm{B}} \Lambda \mathrm{v}_{\mathrm{B}}\right)$.

Similarly, if $\mathrm{u} \Lambda_{\mathrm{X}} \mathrm{v} \Leftarrow \mathrm{v}$, then also we can prove $\mathrm{u} \Lambda_{\mathrm{N}} \mathrm{v}=\left(0, \mathrm{u}_{\mathrm{B}} \Lambda \mathrm{v}_{\mathrm{B}}\right)$

Case 2:

Thus in this case $\mathrm{u} \Lambda_{\mathrm{N}} \mathrm{v}=\left(0, \mathrm{u}_{\mathrm{B}} \Lambda \mathrm{v}_{\mathrm{B}}\right)$

$\mathrm{u} \Lambda_{\mathrm{X}} \mathrm{v}$ is a lower bound of both $\mathrm{u}$ and $\mathrm{v}$ in $\mathrm{N}(\mathrm{A}, \mathrm{B}, \theta)$.

If $\mathrm{t} \Leftarrow_{\mathrm{N}} \mathrm{u} \Lambda_{\mathrm{x}} \mathrm{v}$, then by (1.2.4.) $\mathrm{t}_{\mathrm{A}}, \mathrm{u}_{\mathrm{A}} \Lambda \mathrm{v}_{\mathrm{A}} \in \mathrm{A}^{-}$and [t, $\left.\mathrm{u} \Lambda_{\mathrm{x}} \mathrm{v}\right]$ is not $\theta$-discrete.

Since $\mathrm{u}_{\mathrm{A}} \Lambda \mathrm{v}_{\mathrm{A}} \in \mathrm{A}^{-}$, it follows that $\mathrm{u}_{\mathrm{A}} \in \mathrm{A}^{-}$or $\mathrm{v}_{\mathrm{A}} \in \mathrm{A}^{-}$or both $\mathrm{u}_{\mathrm{A}} \in \mathrm{A}^{-}$and $\mathrm{v}_{\mathrm{A}} \in \mathrm{A}^{-}$.

Suppose $\mathrm{u}_{\mathrm{A}} \in \mathrm{A}^{-}$.

Since $\mathrm{t} \leq_{\mathrm{N}} \mathrm{u}$ and $\mathrm{t}_{\mathrm{A}}, \mathrm{u}_{\mathrm{A}} \in \mathrm{A}^{-}$, we conclude that $[\mathrm{t}, \mathrm{u}]$ is $\theta$-discrete by (i) of proposition 1.2.3.

This contradicts the fact that $\left[\mathrm{t}, \mathrm{u} \Lambda_{\mathrm{X}} \mathrm{v}\right]$ is not $\theta$-discrete.

Hence $\mathrm{t} \leq_{\mathrm{N}} \mathrm{u} \Lambda_{\mathrm{X}} \mathrm{v}$.

Thus any lower bound of both $\mathrm{u}$ and $\mathrm{v}$ is $\leq_{\mathrm{N}} \mathrm{u} \Lambda_{\mathrm{X}} \mathrm{v}$.

Hence $\mathrm{u} \Lambda_{\mathrm{N}} \mathrm{v}=\mathrm{u} \Lambda_{\mathrm{X}} \mathrm{v}$.

Similarly if $\mathrm{v}_{\mathrm{A}} \in \mathrm{A}^{-}$, then also $\mathrm{u} \Lambda_{\mathrm{N}} \mathrm{v}=\mathrm{u} \Lambda_{\mathrm{X}} \mathrm{v}$.

Thus in case $2, \mathrm{u} \Lambda_{\mathrm{N}} v=\mathrm{u} \Lambda_{\mathrm{X}} \mathrm{v}$.

Hence $(*)$ holds in N(A, B, $\theta)$.

By duality $(* *)$ holds in $\mathrm{N}(\mathrm{A}, \mathrm{B}, \theta)$.

Hence $\mathrm{N}(\mathrm{A}, \mathrm{B}, \theta)$ is a lattice. 
DEFINITION: 3.3.1

\section{The Congruences On N (A, B, $\theta)$}

Let A be a bounded lattice. A congruence $\Phi$ of A is said to separate 0 if [0] $\Phi=\{0\}$.

That is $\mathrm{x} \equiv 0(\Phi)$ implies that $\mathrm{x}=0$.

DEFINITION: 3.3.2

Let A be a bounded lattice. A congruence $\Phi$ of A is said to separate 1 if $[1](\Phi)=\{1\}$.

That is $\mathrm{x} \equiv 1(\Phi)$ implies that $\mathrm{x}=1$.

DEFINITION: 3.3.3

Let $\mathrm{A}$ be a bounded lattice. Then $\mathrm{A}$ is said to be non-separating if neither 0 nor 1 is separated by any congruence $\Phi \neq \omega$ of A.

NOTE : 3.3.4

In this section, we assume that A is a non-separating finite lattice with more than two elements. B is a finite lattice with more than one element and $\theta>\omega$ is a discrete-transitive congruence on B.

\section{LEMMA: 3.3.5}

Let $\psi$ be a congruence relation on $\mathrm{N}(\mathrm{A}, \mathrm{B}, \theta)$. Define $\psi_{*} \quad$ and $\psi^{*}$ as the restriction of $\psi$ to $\mathrm{B} *$ and $\mathrm{B}^{*}$ respectively. Since $\mathrm{B}_{*}$ and $\mathrm{B} *$ are isomorphic to $\mathrm{B}$, we can view $\psi *$ and $\psi^{*}$ as congruences on $\mathrm{B}$.

Then $\psi_{*}=\psi^{*}$.

Proof : -

Let $\mathrm{b}_{0} \equiv \mathrm{b}_{1}\left(\psi_{*}\right)$.

Then $\left(0, b_{0}\right) \equiv\left(0, b_{1}\right)(\psi)$

Joining both sides with $(1,0)$ we get

$\left(0, \mathrm{~b}_{0}\right) \mathrm{V}(1,0) \equiv\left(0, \mathrm{~b}_{1}\right) \mathrm{V}(1,0)(\psi)$

That is $\left(1, b_{0}\right) \equiv\left(1, b_{1}\right)(\psi)$

That is $\mathrm{b}_{0} \equiv \mathrm{b}_{1}\left(\psi^{*}\right)$

Thus $\mathrm{b}_{0} \equiv \mathrm{b}_{1}\left(\psi_{*}\right)$ implies $\mathrm{b}_{0} \equiv \mathrm{b}_{1}\left(\psi^{*}\right)$.

Hence $\psi * \leq \psi^{*}$.

Similarly, we can prove that $\mathrm{x} \equiv \mathrm{y}\left(\psi^{*}\right)$ implies $\mathrm{x} \equiv \mathrm{y}\left(\psi_{*}\right)$.

Hence $\psi^{*} \leq \psi_{*}$

Thus we get $\psi^{*}=\psi *$

\section{NOTE: 3.3.6}

Let $\psi$ be a congruence relation on $\mathrm{N}(\mathrm{A}, \mathrm{B}, \theta)$. For any $\mathrm{b} \in \mathrm{B}, \mathrm{A}_{\mathrm{b}}$ is isomorphic to A. Define $\psi_{\mathrm{b}}$ as the restriction of $\psi$ to $\mathrm{A}_{\mathrm{b}}$. Then $\psi_{\mathrm{b}}$ is a congruence on $\mathrm{A}$.

\section{LEMMA: 3.3.7}

Let $\psi$ be a congruence relation on $\mathrm{N}(\mathrm{A}, \mathrm{B}, \theta)$. The congruences $\psi_{*}=\psi^{*}$ of $\mathrm{B}$ and the family of congruences $\left\lceil\psi=\left\{\psi_{\mathbf{b}} / \mathrm{b} \in \mathrm{B}\right\}\right.$ of A describe the congruence $\psi$ of N(A,B, $\left.\theta\right)$.

Proof :collapses.

We know that in a finite lattice a congruence is completely determined by the set of prime intervals it

Every prime interval of $\mathrm{N}(\mathrm{A}, \mathrm{B}, \theta)$ is in one of the sublattices $\mathrm{B}_{*}, \mathrm{~B}^{*}$ or $\mathrm{A}_{\mathrm{b}}$ for some $\mathrm{b} \in \mathrm{B}$, or is perspective to a prime interval of $\mathrm{B} *$.

Hence $\psi$ is determined by $\psi_{*}=\psi^{*}$ or by $\left\{\psi_{\mathbf{b}} / \mathrm{b} \in \mathrm{B}\right\}$.

LEMMA : 3.3.8

Hence the lemma.

Let $\psi$ be a congruence relation on $\mathrm{N}(\mathrm{A}, \mathrm{B}, \theta)$. For any $\mathrm{b} \in \mathrm{B}$, let $\psi_{\mathrm{b}}$ be the restriction of $\psi$ to $\mathrm{A}_{\mathrm{b}}$. The family of congruences $\left\lceil\psi=\left\{\psi_{b} / b \in B\right\}\right.$ is either $\left\{\omega_{A} / b \in B\right\}$ or $\left\{i_{A} / b \in B\right\}$.

Proof :-

Let us assume that $x<y \in A_{b}$ for some $b \in B$ and $x \equiv y(\psi)$.

Since $A$ is non-separating, we can assume that $x\left(0, x_{B}\right)$ the zero of $A_{b}$.

$\left(0, \mathrm{x}_{\mathrm{B}}\right) \equiv \mathrm{y}(\psi) \Rightarrow\left(0, \mathrm{x}_{\mathrm{B}}\right) \mathrm{V}(0,1) \equiv(0,1) \mathrm{V} \mathrm{y}(\psi)$

But $(0,1)<(0,1) \mathrm{V}$ y.

$$
\Rightarrow \quad(0,1) \equiv(0,1) \mathrm{V} y(\psi)
$$

So we can assume that $\mathrm{x}<\mathrm{y}$ in $\mathrm{A}_{1}$. 
As $\mathrm{A}$ is non-separating, $\mathrm{x}, \mathrm{y} \in \mathrm{A}_{1}, \mathrm{x} \equiv \mathrm{y}(\psi)$, we can assume that

$\mathrm{y}_{\mathrm{A}}=1$ (ie) $\mathrm{y}=\left(1, \mathrm{y}_{\mathrm{B}}\right)$.

If $\mathrm{x}_{\mathrm{A}}=0$, then $\psi_{1}=\mathrm{i}_{\mathrm{A}}$.

The congruence $\mathrm{x} \equiv \mathrm{y}(\psi)$ implies $(1, \mathrm{~b}) \Lambda \mathrm{x} \equiv(1, \mathrm{~b}) \Lambda \mathrm{y}(\psi)$

That is $(0, \mathrm{~b}) \equiv(1, \mathrm{~b})(\psi)$

Hence $\psi_{\mathrm{b}}=\mathrm{i}_{\mathrm{A}}$

Suppose $\mathrm{x}_{\mathrm{A}} \neq 0$

$\theta>\omega$ by assumption. So, the interval $[0,1]$ of $B$ is not $\theta$-discrete.

$\mathrm{x} \equiv \mathrm{y}(\psi)$ implies $\mathrm{x} \Lambda(1,0) \equiv \mathrm{y} \Lambda(1,0)(\psi)$.

That is $(1,0) \equiv(0,0)(\psi)$.

That is $\psi_{0}=\mathrm{i}_{\mathrm{A}}$.

$(1,0) \equiv(0,0)(\psi)$ implies $(1,0) \mathrm{V}(0, \mathrm{~b}) \equiv(0,0) \mathrm{V}(0, \mathrm{~b})(\psi)$

That is $(1, \mathrm{~b}) \equiv(0, \mathrm{~b})(\psi)$

Hence $\psi_{\mathrm{b}}=\mathrm{i}_{\mathrm{A}}$.

\section{LEMMA: 3.3.9}

Let $\mathrm{A}$ be a finite non-separating lattice with more than two elements. Let $\mathrm{B}$ be a finite lattice with more than one element and $\theta>\omega$ be a discrete -transitive congruence on B. Consider N(A,B, $\theta)$. For every congruence $\Phi$ of $B$, there exists a unique minimal congruence $\mathrm{N}(\Phi)$ of $\mathrm{N}(\mathrm{A}, \mathrm{B}, \theta)$ satisfying $\mathrm{N}(\Phi) *=\mathrm{N}(\Phi)^{*}=$ $\Phi$. The congruence $\mathrm{N}(\Phi)$ of $\mathrm{N}(\mathrm{A}, \mathrm{B}, \theta)$ can be described as follows :

\section{Proof :-}

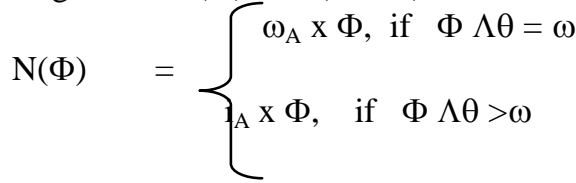

Case1: Let us assume that $\Phi \Lambda \theta=\omega$

Let $\psi=\omega_{\mathrm{A}} \times \Phi$

As $\omega_{\mathrm{A}}$ and $\Phi$ are equivalence relations, $\psi$ is also an equivalence relation.

Let $\mathrm{x} \equiv \mathrm{y}(\psi)$. Then $\mathrm{x}_{\mathrm{A}} \equiv \mathrm{y}_{\mathrm{A}}\left(\omega_{\mathrm{A}}\right)$ and $\mathrm{x}_{\mathrm{B}} \equiv \mathrm{y}_{\mathrm{B}}(\Phi)$

As $\omega_{A}$ and $\Phi$ are congruence relations we have

$\mathrm{x}_{\mathrm{A}} \Lambda \mathrm{y}_{\mathrm{A}} \equiv \mathrm{x}_{\mathrm{A}} \mathrm{Vy}_{\mathrm{A}}\left(\omega_{\mathrm{A}}\right)$ and $\mathrm{x}_{\mathrm{B}} \Lambda \mathrm{y}_{\mathrm{B}} \equiv \mathrm{x}_{\mathrm{B}} \mathrm{Vy}_{\mathrm{B}}(\Phi)$

Hence we have $\mathrm{x} \Lambda \mathrm{y} \equiv \mathrm{xVy}(\psi)$.

To prove $\psi$ is a congruence relation, it is sufficient to verify that

$(* * *)$ For $\mathrm{x}, \mathrm{y} \in \mathrm{N}(\mathrm{A}, \mathrm{B}, \theta)$ with $\mathrm{x}<\mathrm{y}$ and for $\mathrm{t} \in \mathrm{N}(\mathrm{A}, \mathrm{B}, \theta)$

if $\mathrm{x} \equiv \mathrm{y}(\psi)$ then $\mathrm{x} \Lambda \mathrm{t} \equiv \mathrm{y} \Lambda \mathrm{t}(\psi)$ and $\mathrm{xVt} \equiv \mathrm{yVt}(\psi)$.

Let $\mathrm{x} \equiv \mathrm{y}(\psi)$. Then $\mathrm{x}_{\mathrm{A}} \equiv \mathrm{y}_{\mathrm{A}}\left(\omega_{\mathrm{A}}\right)$ and $\mathrm{x}_{\mathrm{B}} \equiv \mathrm{y}_{\mathrm{B}}(\Phi)$.

$\mathrm{x}_{\mathrm{A}} \equiv \mathrm{y}_{\mathrm{A}}\left(\omega_{\mathrm{A}}\right)$ implies $\mathrm{x}_{\mathrm{A}}=\mathrm{y}_{\mathrm{A}}$.

Thus we have $\mathrm{x}_{\mathrm{A}}=\mathrm{y}_{\mathrm{A}} \rightarrow(1)$ and $\mathrm{x}_{\mathrm{B}} \equiv \mathrm{y}_{\mathrm{B}}(\Phi) \rightarrow(2)$

We have to prove $\mathrm{x} \Lambda \mathrm{t} \equiv \mathrm{y} \Lambda \mathrm{t}(\Phi)$.

That is $(\mathrm{x} \Lambda \mathrm{t})_{\mathrm{A}}=(\mathrm{y} \Lambda \mathrm{t})_{\mathrm{A}} \rightarrow(3)$ and

$(\mathrm{x} \Lambda \mathrm{t})_{\mathrm{B}} \equiv(\mathrm{y} \Lambda \mathrm{t})_{\mathrm{B}}(\Phi) \rightarrow(4)$

By lemma (3.2.6) $(*),(x \Lambda t)_{B}=x_{B} \Lambda t_{B}$ and $(y \Lambda t)_{B}=y_{B} \Lambda t_{B}$.

Hence (4) can be written as $\mathrm{x}_{\mathrm{B}} \Lambda \mathrm{t}_{\mathrm{B}} \equiv \mathrm{y}_{\mathrm{B}} \Lambda \mathrm{t}_{\mathrm{B}}(\Phi)$.

By (2) $\mathrm{x}_{\mathrm{B}} \equiv \mathrm{y}_{\mathrm{B}}(\Phi)$ and $\Phi$ is a congruence on $\mathrm{B}$.

implies $\mathrm{x}_{\mathrm{B}} \Lambda \mathrm{t}_{\mathrm{B}} \equiv \mathrm{y}_{\mathrm{B}} \Lambda \mathrm{t}_{\mathrm{B}}(\Phi)$.

Hence (4) holds.

It remains to prove that $(\mathrm{x} \Lambda \mathrm{t})_{\mathrm{A}}=(\mathrm{y} \Lambda \mathrm{t})_{\mathrm{A}} \rightarrow(3)$

By assumption, $\Phi \Lambda \theta=\omega$

Hence $\mathrm{x}_{\mathrm{B}} \Lambda \mathrm{t}_{\mathrm{B}} \equiv \mathrm{y}_{\mathrm{B}} \Lambda \mathrm{t}_{\mathrm{B}}(\Phi)$ can be written as

$\left[\mathrm{x}_{\mathrm{B}} \Lambda \mathrm{t}_{\mathrm{B}}, \mathrm{y}_{\mathrm{B}} \Lambda \mathrm{t}_{\mathrm{B}}\right]$ is $\theta$-discrete $\rightarrow(5)$

$(\mathrm{y} \Lambda \mathrm{t})_{\mathrm{A}}=\mathrm{y}_{\mathrm{A}} \Lambda \mathrm{t}_{\mathrm{A}}$ or $(\mathrm{y} \Lambda \mathrm{t})_{\mathrm{A}}=0$ (by lemma 3.2.6 (*))

If $(\mathrm{y} \Lambda \mathrm{t})_{\mathrm{A}}=0$, then $(\mathrm{x} \Lambda \mathrm{t})_{\mathrm{A}} \leq(\mathrm{y} \Lambda \mathrm{t})_{\mathrm{A}}=0$ implies $(\mathrm{x} \Lambda \mathrm{t})_{\mathrm{A}}=0$.

Hence $(\mathrm{x} \Lambda \mathrm{t})_{\mathrm{A}}=(\mathrm{y} \Lambda \mathrm{t})_{\mathrm{A}}=0$

Hence (3).

Suppose $(\mathrm{y} \Lambda \mathrm{t})_{\mathrm{A}}=\mathrm{y}_{\mathrm{A}} \Lambda \mathrm{t}_{\mathrm{A}}$. That is $\mathrm{y} \Lambda \mathrm{t}=\mathrm{y} \Lambda_{\mathrm{X}} \mathrm{t}$.

Then we prove that $\mathrm{x} \Lambda \mathrm{t}=\mathrm{x} \Lambda_{\mathrm{X}} \mathrm{t}$ and from this (3) follows $\mathrm{y} \Lambda \mathrm{t}=\mathrm{y} \Lambda_{\mathrm{X}} \mathrm{t}$. 
By lemma (1.2.6) $(*)$, this is equivalent to

$\mathrm{y} \Lambda \mathrm{t} \leq_{\mathrm{N}} \mathrm{y}$ and $\mathrm{y} \Lambda \mathrm{t} \leq_{\mathrm{N}} \mathrm{t}$, which can be rewritten as follows :

One of the following conditions holds :

$$
\begin{array}{rlll}
\mathrm{y}_{\mathrm{A}} \Lambda \mathrm{t}_{\mathrm{A}}=0 & \text { or } & 1 & \rightarrow(1 \mathrm{a}) \\
\mathrm{y}_{\mathrm{A}}=0 & \text { or } & 1 & \rightarrow(1 \mathrm{~b})
\end{array}
$$

$\left[\mathrm{y}_{\mathrm{B}} \Lambda \mathrm{t}_{\mathrm{B}}, \mathrm{y}_{\mathrm{B}}\right]$ is $\theta$-discrete $\rightarrow(1 \mathrm{c})$

and one of the following conditions holds :

$\mathrm{y}_{\mathrm{A}} \Lambda \mathrm{t}_{\mathrm{A}}=0 \quad$ or $1 \rightarrow(2 \mathrm{a})$

$$
\mathrm{t}_{\mathrm{A}}=0 \text { or } 1 \rightarrow(2 \mathrm{~b})
$$

$\left[\mathrm{y}_{\mathrm{B}} \Lambda \mathrm{t}_{\mathrm{B}}, \mathrm{t}_{\mathrm{B}}\right]$ is $\theta$-discrete -->(2c)

We have to prove that $\mathrm{x} \Lambda \mathrm{t}=\mathrm{x} \Lambda_{\mathrm{X}} \mathrm{t}$

By, lemma (1.2.6) (*), this is equivalent to $\mathrm{x} \Lambda \mathrm{t} \leq_{\mathrm{N}} \mathrm{x}$ and $\mathrm{x} \Lambda \mathrm{t} \leq_{\mathrm{N}} \mathrm{t}$

That is one of the following conditions holds :

$$
\begin{aligned}
\mathrm{x}_{\mathrm{A}} \Lambda \mathrm{t}_{\mathrm{A}}=0 & \text { or } 1 \rightarrow \quad \text { (3a) } \\
\mathrm{x}_{\mathrm{A}}=0 & \text { or } 1
\end{aligned}
$$

$\left[\mathrm{x}_{\mathrm{B}} \Lambda \mathrm{t}_{\mathrm{B}}, \mathrm{x}_{\mathrm{B}}\right]$ is $\theta$-discrete $\rightarrow(3 \mathrm{c})$

and one of the following conditions holds :

$$
\begin{gathered}
\mathrm{x}_{\mathrm{A}} \Lambda \mathrm{t}_{\mathrm{A}}=0 \quad \text { or } 1 \rightarrow \\
\mathrm{t}_{\mathrm{A}}=0 \text { or } \quad 1 \rightarrow(4 \mathrm{~b})
\end{gathered}
$$

$\left[\mathrm{x}_{\mathrm{B}} \Lambda \mathrm{t}_{\mathrm{B}}, \mathrm{t}_{\mathrm{B}}\right]$ is $\theta$-discrete $\rightarrow(4 \mathrm{c})$

Assume $(1 a, 1 b, 1 c)$

Since $\mathrm{x}_{\mathrm{A}}=\mathrm{y}_{\mathrm{A}}, \quad \mathrm{y}_{\mathrm{A}} \Lambda \mathrm{t}_{\mathrm{A}}=0$ or 1 implies

$\mathrm{x}_{\mathrm{A}} \Lambda \mathrm{t}_{\mathrm{A}}=0$ or 1

Hence (1a) implies (3a).

$\mathrm{x}_{\mathrm{A}}=\mathrm{y}_{\mathrm{A}}, \mathrm{y}_{\mathrm{A}}=0$ or 1 implies $\mathrm{x}_{\mathrm{A}}=0$ or 1 .

Hence (1b) implies (3b).

By (1c) we have $\left[\mathrm{y}_{\mathrm{B}} \Lambda \mathrm{t}_{\mathrm{B}}, \mathrm{y}_{\mathrm{B}}\right.$ ] is $\theta$-discrete.

$\operatorname{By}(5) \quad\left[\mathrm{x}_{\mathrm{B}} \Lambda \mathrm{t}_{\mathrm{B}}, \mathrm{y}_{\mathrm{B}} \Lambda \mathrm{t}_{\mathrm{B}}\right]$ is $\theta$-discrete.

Since $\theta$ is discrete - transitive, we conclude that $\left[\mathrm{x}_{\mathrm{B}} \Lambda \mathrm{t}_{\mathrm{B}}, \mathrm{y}_{\mathrm{B}}\right]$

is $\theta$-discrete.

Hence $\left[\mathrm{x}_{\mathrm{B}} \Lambda \mathrm{t}_{\mathrm{B}}, \mathrm{x}_{\mathrm{B}}\right]$ is $\theta$-discrete $\left(\mathrm{x}_{\mathrm{B}}<\mathrm{y}_{\mathrm{B}}\right)$.

Hence (1c) implies (3c).

Thus (1a, 1b, 1c) imply (3a, 3b, 3c).

\section{Next assume that $(2 a, 2 b, 2 c)$ hold.}

Since $\mathrm{x}_{\mathrm{A}}=\mathrm{y}_{\mathrm{A}}, \mathrm{y}_{\mathrm{A}} \Lambda \mathrm{t}_{\mathrm{A}}=0$ or 1 implies $\mathrm{x}_{\mathrm{A}} \Lambda \mathrm{t}_{\mathrm{A}}=0$ or 1

That is (2a) implies (4a).

By (2b) $t_{A}=0$ or 1 , which is the same as $(4 b)$.

Finally $(2 \mathrm{c})$ gives $\left[\mathrm{y}_{\mathrm{B}} \Lambda \mathrm{t}_{\mathrm{B}}, \mathrm{t}_{\mathrm{B}}\right]$ is $\theta$-discrete.

By (5) $\left[\mathrm{x}_{\mathrm{B}} \Lambda \mathrm{t}_{\mathrm{B}}, \mathrm{y}_{\mathrm{B}} \Lambda \mathrm{t}_{\mathrm{B}}\right]$ is $\theta$-discrete.

Since $\theta$ is discrete-transitive, we conclude that

$\left[\mathrm{x}_{\mathrm{B}} \Lambda \mathrm{t}_{\mathrm{B}}, \mathrm{t}_{\mathrm{B}}\right]$ is $\theta$-discrete.

Hence $(4 \mathrm{c})$.

Thus (2a, 2b, 2c) imply (4a, 4b, 4c).

Thus y $\Lambda \mathrm{t}=\mathrm{y} \Lambda_{\mathrm{x}} \mathrm{t}$ implies x $\Lambda \mathrm{t}=\mathrm{x} \Lambda_{\mathrm{x}} \mathrm{t}$.

Case : 2

Let us assume that $\Phi \Lambda \theta>\omega$

Define $\psi=\mathrm{i}_{\mathrm{A}} \mathrm{X} \Phi$

Then $\psi$ is a congruence relation on $\mathrm{N}(\mathrm{A}, \mathrm{B}, \theta)$.

Moreover $\psi_{*}=\psi^{*}=\Phi$ and $\psi_{\mathrm{b}}=\mathrm{i}_{\mathrm{A}} \quad$ for all $\mathrm{b} \in \mathrm{B}$.

Next we claim that $\mathrm{N}(\Phi)$ is a minimal congruence of $\mathrm{N}(\mathrm{A}, \mathrm{B}, \theta)$ satisfying $\mathrm{N}(\Phi) *=\mathrm{N}(\Phi)^{*}=\Phi$.

Let $\Sigma$ be a congruence of $\mathrm{N}(\mathrm{A}, \mathrm{B}, \theta)$ satisfying $\Sigma_{*}=\Sigma^{*}=\Phi$

Since $\Phi \Lambda \theta>\omega$, we can choose in B the elements $b_{1} \square b_{2}$ such that

$\mathrm{b}_{1} \equiv \mathrm{b}_{2}(\Phi \Lambda \theta)$.

From $\Sigma_{*}=\Phi$, it follows that $\mathrm{b}_{1} \equiv \mathrm{b}_{2}(\Sigma)$ also holds

By assumption, A has more than two elements, so we can 
choose $\mathrm{a} \in \mathrm{A}^{-}$.

$\left(\mathrm{a}, \mathrm{b}_{1}\right) \mathrm{V}\left(0, \mathrm{~b}_{2}\right)=\left(1, \mathrm{~b}_{1} \mathrm{~V} \mathrm{~b}_{2}\right)=\left(1, \mathrm{~b}_{2}\right)$.

Since $\mathrm{b}_{1} \equiv \mathrm{b}_{2}\left(\Sigma_{*}\right)$, it follows that $\left(0, \mathrm{~b}_{1}\right) \equiv\left(0, \mathrm{~b}_{2}\right)(\Sigma)$.

Joining both sides with $\left(a, b_{1}\right)$ we get

$\left(\mathrm{a}, \mathrm{b}_{1}\right) \mathrm{V}\left(0, \mathrm{~b}_{1}\right) \equiv\left(\mathrm{a}, \mathrm{b}_{1}\right) \mathrm{V}\left(0, \mathrm{~b}_{2}\right)(\Sigma)$

$$
\begin{aligned}
\left(\mathrm{a}, \mathrm{b}_{1}\right) & \equiv\left(1, \mathrm{~b}_{2}\right)(\Sigma) \\
\therefore\left(\mathrm{a}, \mathrm{b}_{1}\right) & \equiv\left(1, \mathrm{~b}_{1}\right)(\Sigma) .
\end{aligned}
$$

Thus we get $\Sigma_{\mathrm{b}}>\omega_{\mathrm{A}}$

By lemma (1.3.8), we get $\Sigma_{\mathrm{b}}=\mathrm{p}_{\mathrm{A}} 1$

$\therefore \Sigma_{\mathrm{b}}=\mathrm{i}_{\mathrm{A}}$ for all $\mathrm{b} \in \mathrm{B}$.

Hence $\Sigma \geq \psi$.

$\therefore \psi=\mathrm{N}(\Phi)$ is the smallest congruence of $\mathrm{N}(\mathrm{A}, \mathrm{B}, \theta)$ satisfying

$\psi_{*}=\psi^{*}=\Phi$.

By the lemma (1.3.9), we conclude that to every congruence $\Phi$ of $\mathrm{B}$, we can associate a congruence $\mathrm{N}(\Phi)$ of $\mathrm{N}(\mathrm{A}, \mathrm{B}, \theta)$. In the next lemma, we see some properties of the map which associates $\Phi$ to $\mathrm{N}(\Phi)$.

\section{LEMMA : 1.3.10}

Let $\mathrm{A}$ be a finite non-separating lattice with more than two elements. Let $\mathrm{B}$ be a finite lattice with more than one element and $\theta>\omega$ is a discrete-transitive congruence on $\mathrm{B}$. consider N(A,B, $\theta)$. Define a map $\mathrm{N}: \mathrm{ConB} \rightarrow \operatorname{ConN}(\mathrm{A}, \mathrm{B}, \theta)$ by $\mathrm{N}(\Phi)=\mathrm{N}(\Phi, \mathrm{A}, \mathrm{B}, \theta)$ which is denoted by $\mathrm{N}(\Phi)$.

Then

(i) $\mathrm{N}$ is an order preserving, one-to-one map of ConB into

$\operatorname{ConN}(\mathrm{A}, \mathrm{B}, \theta)$.

(ii) The map $\mathrm{N}$ is an order preserving, one-to-one map of the join irreducible elements of ConB into joinirreducible elements of $\mathrm{ConN}(\mathrm{A}, \mathrm{B}, \theta)$.

(iii) The lattice $\operatorname{ConN}(\mathrm{A}, \mathrm{B}, \theta)$ has exactly one join-irreducible element that is not in the image of $\mathrm{N}$. $\Sigma=\theta$ ( $(0,0),(1,0)), \Sigma$ is a minimal join-irreducible element of $\operatorname{ConN}(\mathrm{A}, \mathrm{B}, \theta)$.

(iv) For a minimal join-irreducible congruence $\Phi$ of $\mathrm{B}$, we have $\Sigma<\mathrm{N}(\Phi)$ iff, $\Phi \leq \theta$.

Proof :-

By lemma 1.3.9., if $\Phi \in \mathrm{ConB}$, then $\mathrm{N}(\Phi)$ is the unique minimal congruence of $\mathrm{N}(\mathrm{A}, \mathrm{B}, \theta)$ such that $\mathrm{N}(\Phi) *=$ $\mathrm{N}(\Phi)^{*}=\Phi$.

Hence if $\Phi_{1}, \Phi_{2} \in \mathrm{ConB}$, and if $\mathrm{N}\left(\Phi_{1}\right)=\mathrm{N}\left(\Phi_{2}\right)$ then $\Phi_{1}=\Phi_{2}$.

That is $\mathrm{N}$ is one-one.

If $\Phi_{1} \leq \Phi_{2}$ then $\mathrm{N}\left(\Phi_{1}\right) \leq \mathrm{N}\left(\Phi_{2}\right)$.

Hence $\mathrm{N}$ is an order preserving one-to-one map of ConB into $\operatorname{ConN}(\mathrm{A}, \mathrm{B}, \theta)$.

A join-irreducible congruence of a finite lattice is one that is generated by a covering pair of elements.

If $\Phi$ is a join-irreducible congruence, then $\Phi=\theta\left(b_{1}, b_{2}\right)$ with

$\mathrm{b}_{1} \square \mathrm{b}_{2}$ in $\mathrm{B}$.

Then $\mathrm{N}(\Phi)=\theta\left(\left(0, \mathrm{~b}_{1}\right),\left(0, \mathrm{~b}_{2}\right)\right)$ and $\left(0, \mathrm{~b}_{1}\right) \square\left(0, \mathrm{~b}_{2}\right)$ in $\mathrm{N}(\mathrm{A}, \mathrm{B}, \theta)$.

$B$ are mapped by $\mathrm{N}$ into join-irreducible congruences of $\mathrm{N}(\mathrm{A}, \mathrm{B}, \theta)$.

So, the join-irreducible congruences of

Also $\mathrm{N}$ is order preserving and one-one.

Hence (ii).

Any prime interval of $N(A, B, \theta)$ is in one of the sublattices $B_{*}, B^{*}$, or $A_{b}$, for some $b \in B$, or is perspective to a prime interval of $\mathrm{B}_{*}$

The prime intervals in $\mathrm{B}_{*}$ and $\mathrm{B}^{*}$ generate the join-irreducible congruences of the form $\mathrm{N}(\Phi)$, where $\Phi$ is a joinirreducible congruence of $\mathrm{B}$.

The remaining prime intervals all generate the same join-irreducible congruence $\Sigma$, by lemma 1.3.8.

Thus the lattice $\operatorname{ConN}(\mathrm{A}, \mathrm{B}, \theta)$ has exactly one join-irreducible element that is not in the image of $\mathrm{N}$.

Hence (iii).

$\Sigma<\mathrm{N}(\Phi)$ holds if, and only if, $\Phi \Lambda \theta>\omega$

If $\Phi \Lambda \theta<\Phi$, then there is a join-irreducible congruence of B, namely $\theta \Lambda \Phi$ properly below $\Phi$, contrary to our assumption.

Therefore $\theta \Lambda \Phi=\Phi$.

That is $\Phi \leq \theta$.

Thus $\Sigma<\mathrm{N}(\Phi)$ if, and only if, $\Phi \leq \theta$. 
Hence (iv) .

Hence the lemma.

\section{REMARK :1.3.11}

Let $\mathrm{D}$ be a finite distributive lattice.

Let $\mathrm{J}(\mathrm{D})$ denote the poset of join-irreducible elements of $\mathrm{D}$.

For a minimal join-irreducible element $\mathrm{p}$ of $\mathrm{D}$, let $\operatorname{Cov}(\mathrm{p})$ denote the covers of $\mathrm{p}$ in $\mathrm{J}(\mathrm{D})$

That is $\operatorname{Cov}(\mathrm{p})=\{\mathrm{q} \in \mathrm{J}(\mathrm{D}) / \mathrm{p} \square \mathrm{q}\}$.

Let $\mathrm{D}^{\prime}$ denote the join-subsemilattice of $\mathrm{D}$ generated by $\mathrm{J}(\mathrm{D})-\{\mathrm{p}\}$.

Then $D^{\prime}$ is a finite distributive lattice with $J\left(D^{\prime}\right)=J(D)-\{p\}$. The set $\operatorname{Cov}(p)$ is an antichain of $J\left(D^{\prime}\right)$.

Conversely, given a finite distributive lattice $D^{\prime}$ and an antichain $C \neq \phi$ of $J\left(D^{\prime}\right)$, we can form the poset $J\left(D^{\prime}\right) \cup$ $\{\mathrm{p}\}$ where $\mathrm{p} \notin \mathrm{J}\left(\mathrm{D}^{\prime}\right)$.

We can extend the partial ordering of $J\left(D^{\prime}\right)$ to $J\left(D^{\prime}\right) \cup\{p\}$ by defining $p<q$ for all $q \in C$.

More precisely, we define $\mathrm{p}<\mathrm{r}$ for every $\mathrm{r} \in \mathrm{J}\left(\mathrm{D}^{\prime}\right)$ for which there exists a $\mathrm{q} \in \mathrm{C}$ satisfying $\mathrm{q} \leq \mathrm{r}$.

The poset $J\left(D^{\prime}\right) \cup\{p\}$ determines a distributive lattice $D$.

$\operatorname{In} \mathrm{D}, \operatorname{Cov}(\mathrm{p})=\mathrm{C}$.

We call D', the distributive lattice obtained from $\mathrm{D}$ by deleting the minimal join-irreducible element $\mathrm{p}$ and we call $\mathrm{D}$, the distributive lattice obtained from $\mathrm{D}$ ' by adding a minimal join-irreducible element under $\mathrm{C}$.

Next we summarize the properties we have learned about the congruence lattice of $N(A, B, \theta)$.

\section{THEOREM: 1.3.12}

Let $\mathrm{A}$ be a finite non-separating lattice with more than two elements. Let $\mathrm{B}$ be a finite lattice with more than one element, and let $\theta>\omega$ be a discrete-transitive congruence on B.

Let $\theta=\Sigma_{1} \mathrm{~V} \Sigma_{2} \mathrm{~V} \ldots . \mathrm{V} \Sigma_{\mathrm{n}}$ be an irredundant representation of $\theta$ as a join of join-irreducible elements and let $\mathrm{C}=\left\{\Sigma_{1}, \Sigma_{2} \ldots \ldots \Sigma_{\mathrm{n}}\right\}$. Let $\Sigma$ be the join-irreducible congruence of $\mathrm{N}(\mathrm{A}, \mathrm{B}, \theta)$ define by $\Sigma=\theta((0,0),(1,0))$.

Then we can obtain, upto isomorphism, the congruence lattice of $\mathrm{N}(\mathrm{A}, \mathrm{B}, \theta)$ by adjoining to the congruence lattice of $\mathrm{B}$, a minimal join-irreducible element under $\mathrm{C}$.

Equivalently, we can obtain, upto isomorphism, the congruence lattice of $\mathrm{B}$ by deleting the minimal join-irreducible element $\Sigma$ of $\operatorname{ConN}(\mathrm{A}, \mathrm{B}, \theta)$.

\section{LEMMA : 1.3.13}

Let $\mathrm{A}$ be a finite non-separating lattice with more than two elements. Let $\mathrm{B}$ be a finite lattice with more than one element and let $\theta>\omega$ be a discrete-transitive congruence on $B$. Consider $N(A, B, \theta)$.

If $\Phi$ is a discrete-transitive congruence of $B$, then the congruence $N(\Phi)$ of $N(A, B, \theta)$ is also a discretetransitive congruence.

Proof :-

Case (1)

Let us assume that $\Phi \Lambda \theta=\omega$

Then $\mathrm{N}(\Phi)=\omega_{\mathrm{A}} \mathrm{x} \Phi$ by lemma (1.3.9).

For elements $a<b \in N(\Phi), a \equiv b(N(\Phi))$ if, and

only if, $\mathrm{a}_{\mathrm{A}}=\mathrm{b}_{\mathrm{A}}$ and $\mathrm{a}_{\mathrm{B}} \equiv \mathrm{b}_{\mathrm{B}}(\Phi)$.

Therefore, an interval $[\mathrm{u}, \mathrm{v}]$ of $\mathrm{N}(\mathrm{A}, \mathrm{B}, \theta)$ is $\mathrm{N}(\Phi)$-discrete if, and only if, the interval $\left[\mathrm{u}_{\mathrm{B}}, \mathrm{v}_{\mathrm{B}}\right]$ of $\mathrm{B}$ is $\Phi$ discrete.

Case (2)

Therefore, if $\Phi$ is discrete-transitive in $\mathrm{B}$, then $\mathrm{N}(\Phi)$ is discrete- transitive in N(A,B, $\theta)$.

Let us assume that $\Phi \Lambda \theta>\omega$.

Then $\mathrm{N}(\Phi)=\mathrm{i}_{\mathrm{A}} \times \Phi$ by lemma (1.3.9).

Then an interval $[\mathrm{u}, \mathrm{v}]$ of $\mathrm{N}(\mathrm{A}, \mathrm{B}, \theta)$ is $\mathrm{N}(\Phi)$ discrete if, and only if, $\mathrm{u}_{\mathrm{A}}=\mathrm{v}_{\mathrm{A}}$ and the interval $\left[\mathrm{u}_{\mathrm{B}}, \mathrm{v}_{\mathrm{B}}\right]$ of $\mathrm{B}$ is $\Phi$-discrete.

As $\Phi$ is discrete-transitive, it follows that $\mathrm{N}(\Phi)$ is also discrete-transitive.

Hence the lemma.

\section{COROLLARY: 1.3.14}

Let $\mathrm{A}$ be a finite non-separating lattice with more than two elements. Let $\mathrm{B}$ be a finite lattice with more than one element and let $\theta>\omega$ be a discrete-transitive congruence on $\mathrm{B}$. If all congruences of $\mathrm{B}$ are discrete-transitive, then all congruences of $\mathrm{N}(\mathrm{A}, \mathrm{B}, \theta)$ are discrete-transitive. 
Proof :-

First, we observe that the congruence $\Sigma=\theta((0,0),(1,0))$ is discrete - transitive.

Any congruence of $\mathrm{N}(\mathrm{A}, \mathrm{B}, \theta)$ is of the form $\Sigma \mathrm{VN}(\Phi)$ where $\Phi$ is a congruence of B.

We know that the join of two discrete-transitive congruence is discrete-transitive.

Since $\Phi$ is discrete-transitive, $N(\Phi)$ is also discrete-transitive.

Hence $\Sigma \mathrm{VN}(\Phi)$ is discrete-transitive.

Thus all congruences of $\mathrm{N}(\mathrm{A}, \mathrm{B}, \theta)$ are discrete-transitive if all congruences of $\mathrm{B}$ are discrete-transitive.

Hence the result.

\section{The Main Theorem}

In this section we prove the theorem given below:

\section{THEOREM: 4.4.1}

Every finite distributive lattice D can be represented as the congruence lattice of a finite lattice $\mathrm{L}$ with the following properties:

(i) L is isoform.

(ii) For every congruence $\theta$ of $\mathrm{L}$, the congruence classes of $\theta$ are projective intervals.

(iii) $\mathrm{L}$ is a finite pruned Boolean lattice.

(iv) $\mathrm{L}$ is discrete-transitive.

Proof:-

Let $\mathrm{D}$ be a finite distributive lattice.

We have to construct a lattice L satisfying the conditions of the above theorem.

If $\mathrm{D}$ is the one-element lattice, then let $\mathrm{L}$ be the one-element lattice.

If $\mathrm{D}$ has more than one element, then $\mathrm{J}(\mathrm{D}) \neq \phi$.

We prove the result using induction on $n=|J(D)|$.

If $|\mathrm{J}(\mathrm{D})|=\mathrm{n}=1$, then let $\mathrm{L}=\mathrm{C}_{2}$.

If $|J(D)|=2$, then either $J(D)$ is unordered or $J(D)$ is a two-element chain.

If $\mathrm{I}(\mathrm{N})$ is unordared shonce $\mathrm{L}=\mathrm{C}_{2}{ }^{2}$

(ie)

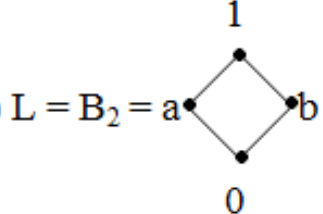

If $\mathrm{J}(\mathrm{D})$ is the two element chain, then choose $\mathrm{L}$ as the lattice given below.

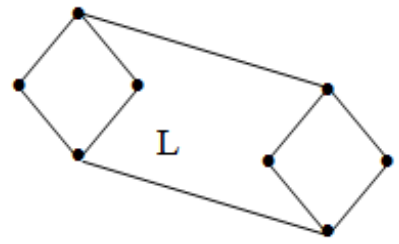

Then L satisfies the conditions of the above theorem.

By induction assumption assume that the result is true when

$|\mathrm{J}(\mathrm{D})|<\mathrm{n}$.

Now, we prove the result when $|\mathrm{J}(\mathrm{D})|=\mathrm{n}>2$.

If $J(D)$ is an antichain, the theorem follows, by choosing the lattice $\mathrm{L}$ as the Boolean lattice with $\mathrm{n}$ atoms.

If $J(D)$ is not an antichain, choose a minimal but not maximal join-irreducible element $\mathrm{p}$ of $\mathrm{D}$.

Let $D^{\prime}$ be the distributive lattice join-generated by $J(D)-\{p\}$.

Then $\left|\mathrm{J}\left(\mathrm{D}^{\prime}\right)\right|=\mathrm{n}-1$.

Then by induction assumption, there is a lattice B and a lattice isomorphism $\alpha: \mathrm{D}^{\prime} \rightarrow$ Con B satisfying the conditions of the above theorem.

Since $\mathrm{p}$ is not a maximal element of $\mathrm{J}(\mathrm{D})$, it follows that $\operatorname{Cov}(\mathrm{p}) \neq \phi$.

Let $\mathrm{q} \in \operatorname{Cov}(\mathrm{p})$.

Since $\mathrm{q} \in \mathrm{D}^{\prime}$, under the isomorphism $\alpha$ is mapped to a congruence $\theta_{\mathrm{q}}$ of $\mathrm{B}$.

Define $\theta=\mathrm{V}\{\theta \mathrm{q} \mid \mathrm{q} \in \operatorname{Cov}(\mathrm{p})\}$ 
Let $\mathrm{L}=\mathrm{N}\left(\mathrm{B}_{2}, \mathrm{~B}, \theta\right)$

By theorem 1.3.12., Con $\mathrm{L} \cong \mathrm{D}$.

Now, we have to prove $\mathrm{L}$ satisfies conditions (i) to (iv) of the theorem.

Let $\psi$ be a congruence of $\mathrm{L}$.

Then $\psi$ is one of the following forms by lemma 3.3.9, lemma 3.3.10 and theorem1.3.11.

Form : 1

$\psi=\mathrm{N}(\Phi)=\omega_{\mathrm{A}} \mathrm{x} \Phi$, where $\Phi$ is a congruence of B satisfying

$\theta \Lambda \Phi=\omega$.

Form: 2

$\psi=\mathrm{N}(\Phi)=\mathrm{i}_{\mathrm{A}} \mathrm{x} \Phi$, where $\Phi$ is a congruence of B satisfying $\Phi \Lambda \theta>\omega$.

Form : 3

$\psi=\mathrm{N}(\Phi) \mathrm{V} \Sigma$, where $\Phi$ is a congruence of $\mathrm{B}$.

Form $1: \psi=\mathrm{N}(\Phi)=\omega_{\mathrm{A}} \times \Phi$.

Then the congruence classes of $\mathrm{N}(\Phi)$ are described as follows.

Let $[u, v]$ be a congruence class of $\Phi$ in B.

Then the congruence classes of $\psi$ in $\mathrm{L}$ are exactly the intervals of the form $[(\mathrm{a}, \mathrm{u}),(\mathrm{a}, \mathrm{v})]$ for any $\mathrm{a} \in \mathrm{A}$.

The interval $[\mathrm{u}, \mathrm{v}]$ of $\mathrm{B}$ is isomorphic to the interval $[(\mathrm{a}, \mathrm{u}),(\mathrm{a}, \mathrm{v})]$ of $\mathrm{L}$ by a $\notin \mathrm{A}^{-}$and by lemma 1.2.6.

If $[\mathrm{u}, \mathrm{v}]$ and $\left[\mathrm{u}^{\prime}, \mathrm{v}^{\prime}\right]$ are any two congruence classes of $\Phi$ in $\mathrm{B}$, then $[\mathrm{u}, \mathrm{v}]$ and $\left[\mathrm{u}^{\prime}, \mathrm{v}^{\prime}\right]$ are isomorphic intervals and they are projective by induction hypothesis.

Then $[(a, u),(a, v)]$ and $\left[\left(a^{\prime}, u^{\prime}\right),\left(a^{\prime}, v^{\prime}\right)\right]$ are isomorphic for any $a, a^{\prime} \in A$.

We have to prove that $[(\mathrm{a}, \mathrm{u}),(\mathrm{a}, \mathrm{v})]$ and $\left[\left(\mathrm{a}^{\prime}, \mathrm{u}^{\prime}\right),\left(\mathrm{a}^{\prime}, \mathrm{v}^{\prime}\right)\right]$ are projective.

$[(\mathrm{a}, \mathrm{u}),(\mathrm{a}, \mathrm{v})]$ is perspective to $[(0, \mathrm{u}),(0, \mathrm{v})]$ and $\left[\left(\mathrm{a}^{\prime}, \mathrm{u}^{\prime}\right),\left(\mathrm{a}^{\prime}, \mathrm{v}^{\prime}\right)\right]$ is perspective to $\left[\left(0, \mathrm{u}^{\prime}\right),\left(0, \mathrm{v}^{\prime}\right)\right]$.

Therefore, to prove $[(\mathrm{a}, \mathrm{u}),(\mathrm{a}, \mathrm{v})]$ and $\left[\left(\mathrm{a}^{\prime}, \mathrm{u}^{\prime}\right),\left(\mathrm{a}^{\prime}, \mathrm{v}^{\prime}\right)\right]$ are projective, it is enough to prove $[(0, \mathrm{u}),(0, \mathrm{v})]$ and $\left[\left(0, u^{\prime}\right),\left(0, v^{\prime}\right)\right]$ are projective.

By induction assumption, $[\mathrm{u}, \mathrm{v}]$ and $\left[\mathrm{u}^{\prime}, \mathrm{v}^{\prime}\right]$ are projective.

A trivial induction shows that it is sufficient to verify that if $[\mathrm{u}, \mathrm{v}]$ and $\left[\mathrm{u}^{\prime}, \mathrm{v}^{\prime}\right]$ are perspective, then so are $[(0, \mathrm{u}),(0, \mathrm{v})]$ and $\left[\left(0, \mathrm{u}^{\prime}\right),\left(0, \mathrm{v}^{\prime}\right)\right]$.

By duality it is sufficient to compute this for up perspectives.

So, let $\mathrm{v} \Lambda \mathrm{u}^{\prime}=\mathrm{u}$ and $\mathrm{vVu} \mathrm{u}^{\prime}=\mathrm{v}^{\prime}$.

Then $(0, \mathrm{v}) \Lambda\left(0, \mathrm{u}^{\prime}\right)=(0, \mathrm{u})$ and $(0, \mathrm{v}) \mathrm{V}\left(0, \mathrm{u}^{\prime}\right)=\left(0, \mathrm{v}^{\prime}\right)$.

This completes the proof in this case.

If $\psi$ is of form 2 or form 3, then the congruence classes of $\psi$ are described in lemmas 1.3.9. and 1.3.10. as follows:

Let $[u, v]$ be a congruence class of $\Phi$ in B.

Then the congruence classes of $\psi$ in $L$ are exactly the intervals of $L$ of the form $[(0, u),(1, v)]$.

$[(0, \mathrm{u}),(1, \mathrm{v})]$ is isomorphic to $\mathrm{N}\left(\mathrm{B}_{2},[\mathrm{u}, \mathrm{v}], \mathrm{i}_{[\mathrm{u}, \mathrm{v}]}\right)$.

So, if the intervals $[u, v]$ and $\left[u^{\prime}, v^{\prime}\right]$ of B are isomorphic, so are the intervals $[(0, u),(1, v)]$ and $\left[\left(0, u^{\prime}\right),\left(1, v^{\prime}\right)\right]$ of $L$.

We have to prove that any two congruence classes of $\psi$ are projective intervals.

Let $[u, v]$ and $\left[u^{\prime}, v^{\prime}\right]$ be any two congruence classes of $\Phi$ in B.

Then $[(0, \mathrm{u}),(1, \mathrm{v})]$ and $\left[\left(0, \mathrm{u}^{\prime}\right),\left(1, \mathrm{v}^{\prime}\right)\right]$ are the corresponding $\psi$ classes in $\mathrm{L}$.

If $[u, v]$ is up perspective to $\left[\mathrm{u}^{\prime}, \mathrm{v}^{\prime}\right]$ then $\mathrm{vVu} \mathrm{u}^{\prime}=\mathrm{v}^{\prime}$ and $\mathrm{v} \Lambda \mathrm{u}^{\prime}=\mathrm{u}$.

$\therefore(1, \mathrm{v}) \mathrm{V}\left(0, \mathrm{u}^{\prime}\right)=\left(1, \mathrm{v} \mathrm{V} \mathrm{u}^{\prime}\right)=\left(1, \mathrm{v}^{\prime}\right)$ and

$(1, \mathrm{v}) \Lambda\left(0, \mathrm{u}^{\prime}\right)=\left(0, \mathrm{v} \Lambda \mathrm{u}^{\prime}\right)=(0, \mathrm{u})$

$\therefore[(0, \mathrm{u}),(1, \mathrm{v})]$ and $\left[\left(0, \mathrm{u}^{\prime}\right),\left(1, \mathrm{v}^{\prime}\right)\right]$ are up perspective.

Similarly, if $[\mathrm{u}, \mathrm{v}]$ is down perspective to [u', $\left.\mathrm{v}^{\prime}\right]$, then we get

$[(0, \mathrm{u}),(1, \mathrm{v})]$ and $\left[\left(0, \mathrm{u}^{\prime}\right),\left(1, \mathrm{v}^{\prime}\right)\right]$ are down perspective (by duality).

If $[\mathrm{u}, \mathrm{v}]$ and $\left[\mathrm{u}^{\prime}, \mathrm{v}^{\prime}\right]$ are projective, then $[(0, \mathrm{u}),(1, \mathrm{v})]$ and

$\left[\left(0, u^{\prime}\right),\left(1, v^{\prime}\right)\right]$ are projective by induction.

This completes the proof of conditions (i) and (ii).

Condition (iii) is obvious.

By hypothesis, B is a pruned Boolean lattice.

Of course, $B_{2}$ is a Boolean lattice.

$\mathrm{So}, \mathrm{L}$ is a pruned Boolean lattice.

Finally by corollary 1.3.14, the congruence's of L are discrete-transitive. 


\section{Hence the theorem}

\section{Bibliography}

[1]. G.Gratzer, H.Lakser, and E.T.Schmidt, Congruence lattices of small planar lattices. Proc. Amer. Math. Soc. 123(1995),

26192623.

[2]. G.Gratzer, General Lattice Theory, Second edition, Birkhauser Verlag, Basel, 2010

[3]. G.Gratzer and E.T.Schmidt, Congruence-preserving extensions of finite lattices into sectionally complemented lattice, Proc. Amer.Math.Soc.127(1999), 1903-1915.

[4]. G.Gratzer and F.Wehrung, Proper congruence-preserving extensions of lattices, Acta Math. Hungar. 85(1999),175-185.

[5]. G.Gratzer and E.T.Schmidt, Regular congruence-preserving extensions. Algebra Universalis 46(2008), 119-130.

[6]. G.Gratzer, E.T.Schmidt, and K.Thomsen, Congruence lattices of uniform lattices. Houston. J.Math.29 (2011)

[7]. G.Gratzer and E.T.Schmidt, Finite lattices with isoform congruences. Tatra.Mt.Math.Publ 27(2009), $111-124$.

[8]. G.Gratzer and E.T.Schmidt, Finite lattices and congruences. Algebra Universalis.

[9]. R.Freese-UACALC program-Sec:http://WWW. Math. hawaii. edu/ ralph/UACALC/. 